3. Department of Health. The expert patient: a new approach to chronic disease management for the 2Ist century. London (UK): The Department; 200I.

4. Clinical practice guidelines and conflict of interest. CMAJ 2005;I73(II):I297.

5. Crawford MJ, Rutter D, Manley C, et al. Systematic review of involving patients in the planning and development of health care. BMJ 2002;325(7375): I263.

DOI:I0.1503/cmaj.106024I

\section{Sudden infant death}

\section{syndrome}

The review article about sudden infant death syndrome (SIDS), by Carl Hunt and Fern Hauck, ${ }^{1}$ was enlightening. However, it was somewhat discouraging in its equivocal negation of the utility of postdelivery electrocardiography. It is the contention of this observer that for any baby with a family history of sudden cardiac death, with evidence of conduction defects or ventricular arrhythmia on cardiorespiratory monitoring, or exhibiting apnea neonatorum, investigations must include electrocardiography to test for cardiac channelopathy such as short QT syndrome, long QT syndrome, Brugada syndrome or progressive cardiac conduction defect, any of which would exclude the diagnosis of SIDS.

\section{John Morphet \\ Cardiologist \\ Niagara-on-the-Lake, Ont.}

\section{REFERENCE}

I. Hunt CE, Houck FR. Sudden infant death syndrome. $C M A J$ 2006;174:I86I-9.

DOI:I0.1503/cmaj.ro6or4I

\section{[The authors respond:]}

We appreciate John Morphet's letter and are pleased to respond. In our article, we stated that electrocardiography is not recommended as a routine strategy for assessing future risk of sudden infant death syndrome. ${ }^{1}$ The cost-effectiveness of such screening in infants without a family history of sudden cardiac death has been studied, but the results have been mixed. The authors of the only North American study concluded that electrocardiography was indicated only in selected groups of in- fants, such as those with symptoms related to apnea or bradycardia or with a family history of sudden infant death syndrome or long QT syndrome. ${ }^{2}$

Both short QT syndrome and long QT syndrome have been reported to cause sudden unexpected death in infancy. ${ }^{2,3}$ Our review did not address the indications for electrocardiography in infants with a family history of sudden cardiac death, but we agree that any baby with a family history of sudden unexpected death in infancy, sudden cardiac death, conduction defect or ventricular arrhythmia should undergo electrocardiography.

It was also outside the scope of our review to discuss recommendations for the clinical evaluation of infants who have experienced an apparent lifethreatening event. In a recent review of the yield of diagnostic testing in 243 such infants, electrocardiography was considered to be indicated in only $25 \%$ 
of the cases and all of the electrocardiograms were normal. ${ }^{4}$ There have been 2 reported cases of infants who experienced an apparent life-threatening event attributed to long QT syndrome, and there is I reported case of an infant with Brugada syndrome who experienced an apparent life-threatening event associated with ventricular fibrillation, but his QT interval was normal. ${ }^{5,6}$ Hence, considering the rarity of apparent life-threatening events caused by long QT syndrome or short QT syndrome, there has not been any formal recommendation that all infants experiencing an apparent lifethreatening event should have electrocardiography as part of the clinical evaluation following the event, except insofar as indicated by the baby's specific history and initial clinical evaluation. Although again this is outside the scope of our review, we would agree with this general approach.

\section{Carl E. Hunt}

Department of Pediatrics

Uniformed Services University of the

Health Sciences

Bethesda, Md.

Fern R. Hauck

Departments of Family Medicine and

Public Health Sciences

University of Virginia

Charlottesville, Va.

\section{REFERENCES}

I. Hunt CE, Hauck FR. Sudden infant death syndrome. CMAJ 2006; I74(I3):I86I-9.

2. Zupancic JAF, Triedman JK, Alexander M, et al. Cost-effectiveness and implications of newborn screening for prolongation of QT interval for the prevention of sudden infant death syndrome. $J \mathrm{Pe}$ diatr 2000; $136: 48 \mathrm{I}-9$.

3. Giustetto C, Di Monte F, Wolpert C, et al. Short QT syndrome: clinical findings and diagnostic-therapeutic implications. Eur Heart J 2006;27:2440-7.

4. Brand DA, Altman RL, Purtill K, et al. Yield of diagnostic testing in infants who have had an apparent life-threatening event. Pediatrics 2005;115:885-93.

5. Skinner JR, Chung S-K, Montgomery D, et al Near-miss SIDS due to Brugada syndrome. Arch Dis Child 2005;90:528-9.

6. Schwartz PJ, Priori SG, Dumaine R, et al. A molecular link between the sudden infant death syndrome and the long QT syndrome. $N$ Engl J Med 2000;343:262-7.

DOI:Io.1503/cmaj.I0700I6

\section{Clarification of the CMA's}

\section{position concerning}

\section{induced abortion}

A recent editorial in $C M A{ }^{1}$ and subsequent letters to the editor have raised several questions about the Canadian Medical Association's position on induced abortion. I would like to clarify that position with this illustrative case.

Case: You are a family physician practising at a community health care centre. A 25-year-old patient recently had a positive pregnancy test and estimates that she is 7 weeks' pregnant. She asks if you will perform a therapeutic abortion. If not, will you refer her right away to someone who will perform it? You are morally opposed to abortion. What are your obligations to this patient?

Discussion: CMA policy ${ }^{2}$ states that "a physician should not be compelled to participate in the termination of a pregnancy." In addition, "a physician whose moral or religious beliefs prevent him or her from recommending or performing an abortion should inform the patient of this so that she may consult another physician."

You should therefore advise the patient that you do not provide abortion services. You should also indicate that because of your moral beliefs, you will not initiate a referral to another physician who is willing to provide this service (unless there is an emergency).

However, you should not interfere in any way with this patient's right to obtain the abortion. At the patient's request, you should also indicate alternative sources where she might obtain a referral. This is in keeping with the obligation spelled out in the CMA policy: "There should be no delay in the provision of abortion services."

\section{Jeff Blackmer}

Executive Director, Office of Ethics

Canadian Medical Association

Ottawa, Ont.

\section{REFERENCES}

I. Rodgers S, Downie J. Abortion: ensuring access [editorial]. CMAJ 2006;175(I):9.

2. Induced abortion [CMA policy]. Ottawa $(\mathrm{ON})$ : Canadian Medical Association; 1988

DOI:I0.1503/cmaj.1070035

Editor's note: We received a large number of letters in response to the editorial by Rodgers and Downie, with particular regard to the CMA's policy on induced abortion. We asked the CMA to assist our readers by clarifying their position using a case-based example, which they have provided here. We will not publish any further letters on this topic, unless they present new information or state a new position on this matter.

\section{Corrections}

In the supplement to the March $\mathrm{I}_{3}$ issue of $C M A J,{ }^{1}$ the term "neuropathy" was omitted from a list that appears on page 15 under the heading "Diabetesrelated vasculopathy" and the subheading "Microvasculature." That list should have read as follows: retinopathy, nephropathy, neuropathy.

\section{REFERENCE}

I. Pilote L, Dasgupta K, Guru V, et al. A comprehensive view of sex-specific issues related to cardiovascular disease. CMAJ 2007;176(Suppl):SI-44.

DOI:I0.I503/cmaj.070432

A recent News article ${ }^{1}$ contained an error concerning the vaccine that GlaxoSmithKline is developing. The sentence "GlaxoSmithKline's Cervarix will block HPV strains linked to $80 \%$ of cervical cancers" should have read as follows: "GlaxoSmithKline's Cervarix may block HPV strains linked to $80 \%$ of cervical cancers." We apologize for any inconvenience this error may have caused.

\section{REFERENCE}

I. Comeau P. Debate begins over public funding for $\mathrm{HPV}$ vaccine. $C M A J$ 2007;176(7):913-4

DOI:I0.I503/cmaj.070433 